\title{
Educational $110 \mathrm{kV}$ step-down substation in the scale of $1 / 10$
}

\author{
Alexander Egorov, Anastasia Larionova and Pavel Kovalenko \\ Automated Electrical Systems Department, Ural Federal University named after the first President of Russia B.N. Yeltsin, 19, Mira St., \\ Yekaterinburg, Russia
}

\begin{abstract}
The educational $110 \mathrm{kV}$ step-down substation in the scale of $1 / 10$ is intended for material supplementation of educational processes in higher education institutions training power industry specialists. Lack of continuous and unlimited access of students to power facilities as well as absence of an opportunity to carry out any practical activities there results in severe deficiency in practical knowledge and skills among students. To solve this problem operating material models of substations and separate power equipment were created, both as the visual aid and as laboratory unit scaled in size. The actually operating substation in the scale of 1/10 allows performing and practicing a wide range of educational activities such as designing, constructing, installing, routine switching, etc.
\end{abstract}

\section{Introduction}

"Electrical power systems equipment designer" project has been being in operation within Automated Electrical Systems dept. (Ural Power Engineering Institute, Ural Federal University, Yekaterinburg) since 2013. The primary aim of the project is to improve the materialand-technical and informational infrastructure of the educational processes with the application of scale modeling methods and technologies. Creating the prefabricated scale models of primary and secondary power systems equipment is intended to address various educational challenges associated with the quality of students and technical specialists training in higher education institutions for power engineering industry. More to that, the project framework involves teaching students to design, model, engineer and analyze, opening the opportunities to design and create new proprietary equipment [1].

The designer is implemented based on the scale modeling methods and technologies within the industryrecognized 3D-modeling CAD/CAM systems, e.g. AutoCAD. To date methods and technologies of laser 3D-scanning, reverse engineering and 3D-printing are widely introduced into the designer production process. This kind of approach to the problem allows to prototype the scale models of substations as well as separate primary and secondary power system equipment using different materials with ensuring high external consistency and geometrical equivalence. It opens the perspective of utilizing the models as the actually operating laboratory setup of small dimension and low cost. Another advantage of scale modeling is maintaining the clearness of the visualization of an object under study or under control, providing the "participation effect" or impression of being at power facility.

\section{Goals And Major Challenges}

The main goal of the project is the improvement of students' education quality by means of expanding the material-and-technical and informational infrastructure of the educational processes with new laboratory classes and practical training being developed to take into account typical as well as non-typical power engineering cases. In other words, the project implies preparing and utilizing the power equipment models along with power facilities based on the models produced using original materials as well as digital and printed prototypes of power plants, substations and other power facilities for educational purposes within multiple related courses (electrical machinery, electrical apparatus, power system equipment, automated control systems etc.). Nowadays the study guides publishing and high-volume manufacturing launch of an educational $110 \mathrm{kV}$ stepdown substation are underway in order to teach the students about the equipment external configuration and the corresponding challenges, its hardware components, principle of operation, dedication and functionality, transporting, mounting, assembly, operation, maintenance, and control.

Designing, assembly and printing of the scale models plays an important role at current stage since seeing a demonstrative model of external and internal arrangement of power equipment ensures the tangible conception of the processes physics and dynamics, together with letting the student into the procedures of a power facility construction and O\&M.

"Electrical power systems equipment designer" is described in detail on the example of a $110 \mathrm{kV}$ unit-type substation transformer bay outdoor switchgear. 


\section{Technological Stages of Scale Models Creating}

Creating the scale model of any equipment piece comprises several technological stages by applying the reverse engineering approach.

The first stage is the investigation including the following steps: selecting the best suitable equipment piece of the various models supplied by different manufacturers; collecting the complete set of initial data (photographs, dimensional drawings, equipment registers, technical datasheets etc.). To date the first stage has been successfully accomplished for $110 \mathrm{kV}$ equipment. "Mednaya" 110/20 kV substation (EESK, www.eesk.ru) with 40 MVA TDN transformers (SVEL, www.svel.ru) was selected to be the prototype of the educational $110 \mathrm{kV}$ substation since it is supplied with modern equipment. The investigation was performed using threedimensional laser scanning methods on the substation site in order to proceed with equipment reverse engineering [2]. The technical documentation and dimensional drawings were requested supplemented by the photographs made for the purpose of subsequent digital modeling of the educational $110 \mathrm{kV}$ substation and then manufacturing its physical model in the scale of $1 / 10$. The fragments of the photographs and the drawings are shown in figures $1-4$.

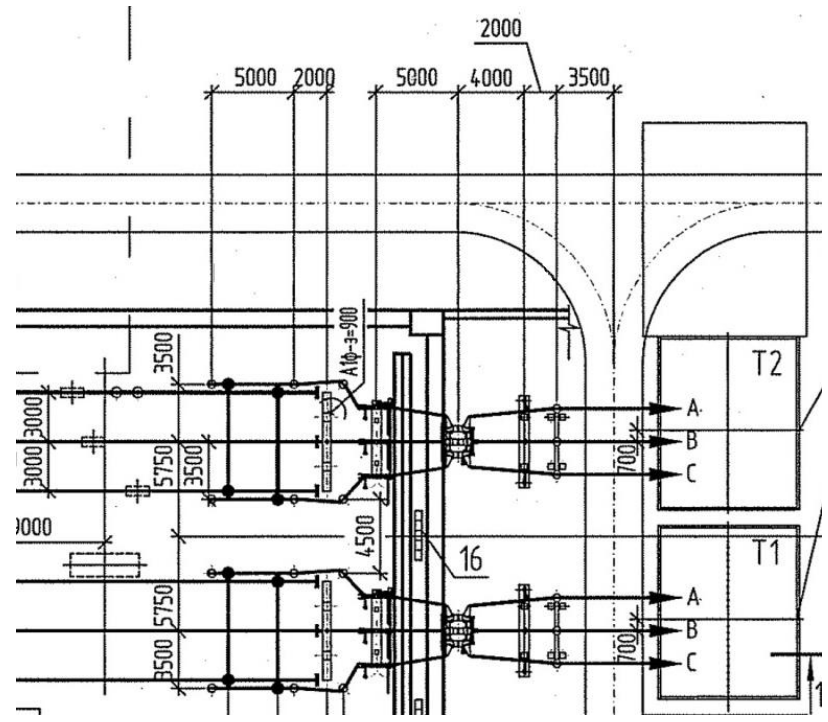

Fig 1. 110/20 kV unit-type substation outdoor switchgear, top view

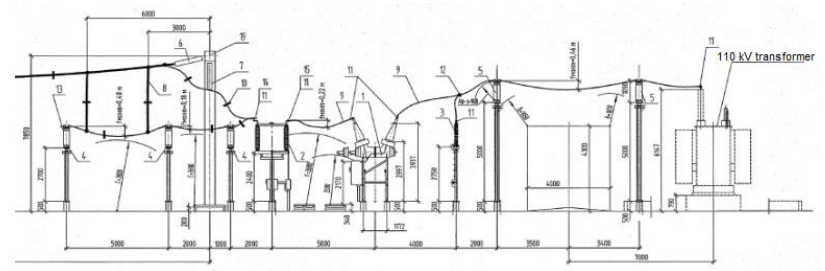

Fig 2. 110/20 kV unit-type substation bay, side view

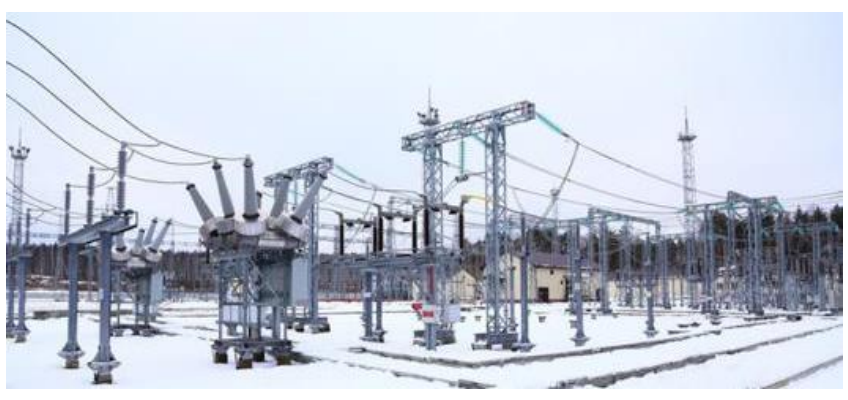

Fig 3. 110/20 kV unit-type substation outdoor switchgear

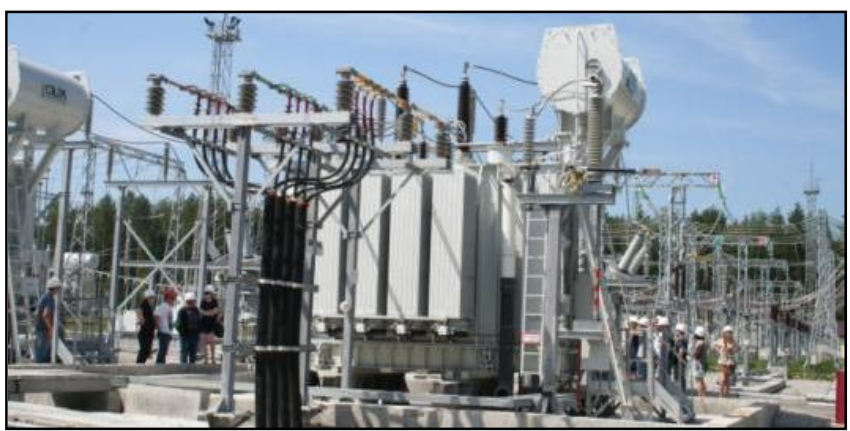

Fig 4. 110/20 kV unit-type substation 40 MVA transformer

The second stage features the collected initial data processing and modeling the power facility exterior and - partially - interior arrangement of the outdoor switchgear components. There were experiments conducted in order to select the optimum scale of the $110 \mathrm{kV}$ outdoor switchgear transformer bay, the results are shown in figure 5 and in table 1.

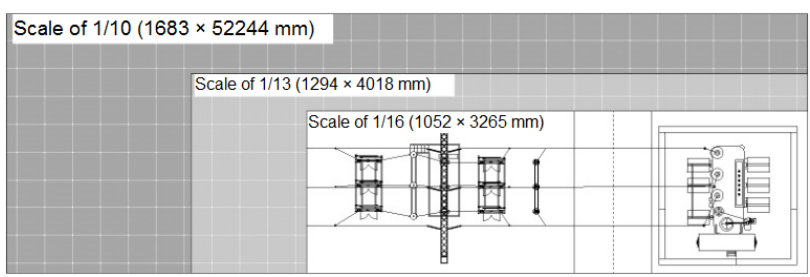

Fig 5. $110 \mathrm{kV}$ outdoor switchgear transformer bay land allocation

Table 1. Area Ratio of the $110 \mathrm{kV}$ Educational Substation

\begin{tabular}{|c|c|c|c|c|}
\hline Scale & Width & Length & Area & $\begin{array}{c}\text { Area } \\
\text { ratio }\end{array}$ \\
\hline $1 / 10$ & $1683 \mathrm{~mm}$ & $5224 \mathrm{~mm}$ & $8,79 \cdot 10^{6} \mathrm{~mm}^{2}$ & $256 \%$ \\
\hline $1 / 13$ & $1294 \mathrm{~mm}$ & $4018 \mathrm{~mm}$ & $5,19 \cdot 10^{6} \mathrm{~mm}^{2}$ & $151 \%$ \\
\hline $1 / 16$ & $1052 \mathrm{~mm}$ & $3265 \mathrm{~mm}$ & $3,43 \cdot 10^{6} \mathrm{~mm}^{2}$ & $100 \%$ \\
\hline
\end{tabular}

The figure and the table clearly show that the transformer bay area in the scale of $1 / 10$ is 2.5 times bigger than the corresponding value in the case of $1 / 16$ scale. However, the scale of $1 / 10$ fits the requirements of introducing the clockwork drives and fitting assortment into separate equipment pieces. Hence the scale of $1 / 10$ was adopted as the generic for the $110 \mathrm{kV}$ outdoor 
switchgear transformer bay with the size of $1.68 \times 5.22 \mathrm{~m}$. Modeling process includes three-dimensional drawing in the scale of $1 / 1$ of separate equipment pieces (see figures 6-12) with full specification and replication of all components, connections, elements and units. This approach preserves the future opportunity to switch to any typical as well as non-typical scale if necessary and if the circumstances require such a transition.

To date the scale range is well-developed and covers the bigger $-1 / 2,1 / 4,1 / 8,1 / 10,1 / 13,1 / 16$ - and the smaller ones $-1 / 20,1 / 24,1 / 35,1 / 48,1 / 72,1 / 100$ и $1 / 144$. The research results defined the decision to continue the project using three scales $-1 / 10,1 / 13,1 / 16$ - since it, beside the reasons given above, ensures the opportunity to install microelectronic components into the equipment pieces.

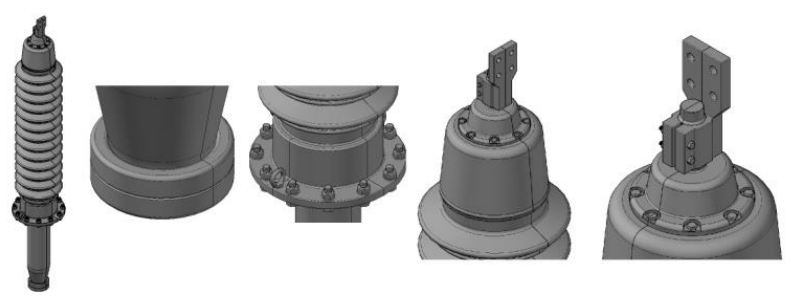

Fig 6. Mosizolyator $110 \mathrm{kV}$ bushing. Detailed: flux shield, bearing flange, bushing cap, clamping arrangement and terminal

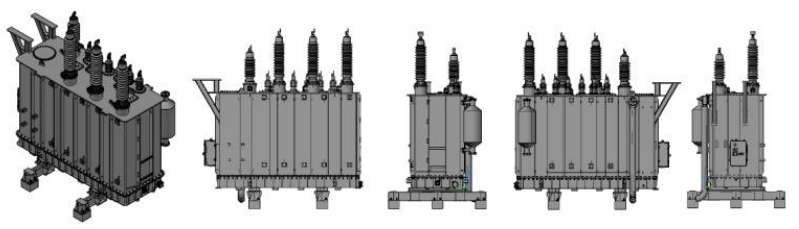

Fig 7. SVEL TDN 110/20 kV 40 MVA transformer (oil conservator removed)
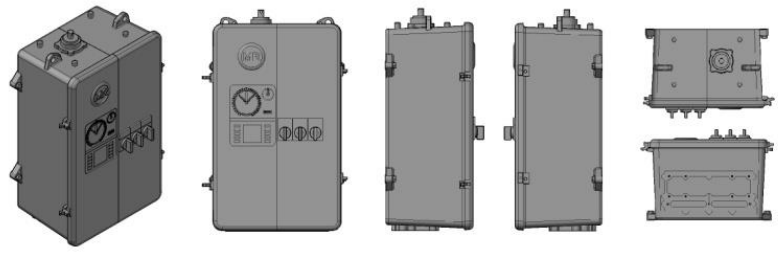

Fig 8. MR on-load tap changer control cabinet (views: front, left, right, top, bottom)
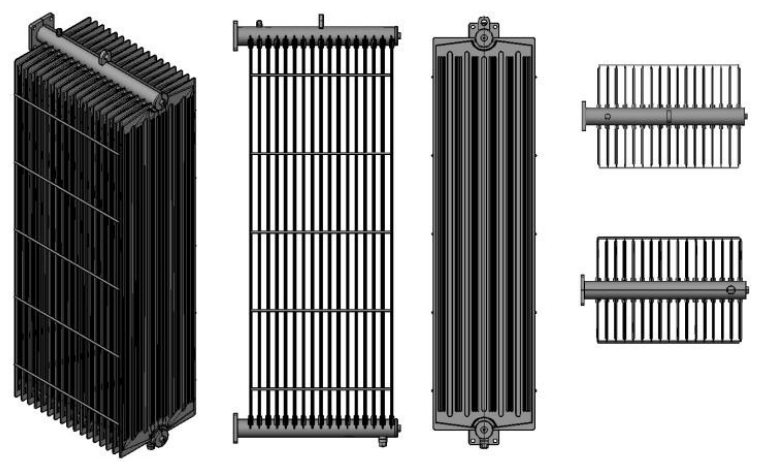

Fig 9. "D" model EuroCooler heatsink (views: left, front, top, bottom)

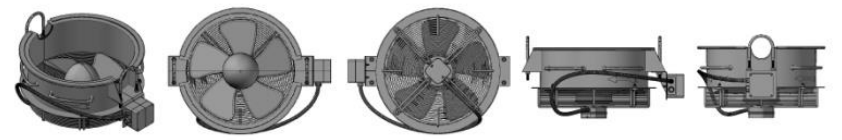

Fig 10. EuroCooler fan (views: top, bottom, left, front)

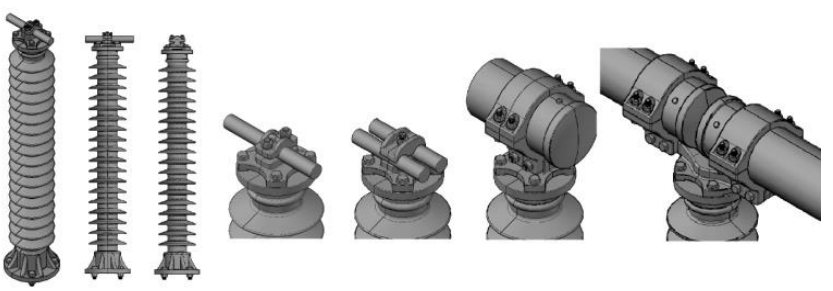

Fig 11. AIZ $110 \mathrm{kV}$ busbar post insulator (2 different versions) with Arutti rigid busbar mounted

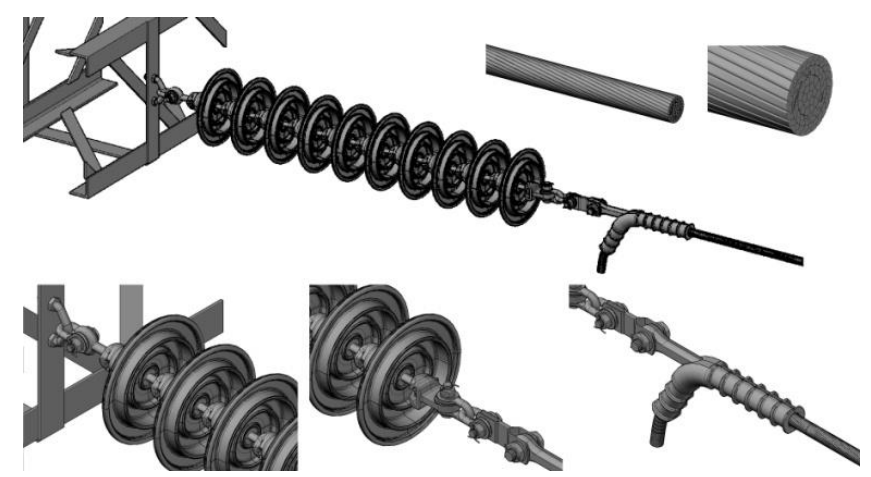

Fig 12. GIG $110 \mathrm{kV}$ outdoor switchgear aluminium-stell $240 \mathrm{~mm}^{2}$ bus system insulator string

After all equipment pieces three-dimensional models have been complete, the substation construction elements - concrete products, metal structures carrying the power equipment - are modelled as well. "BaltTeplostroy" concrete products were adopted as the basis lineup, SVEL group provided the information on metal structures [3]. The third stage includes threedimensional printing of the substation parts using 3Dprinters. 3D-printing technology are utilized for prototyping since they are quite expensive. The technology is involved in manufacturing the prototype of a single $110 \mathrm{kV}$ substation outdoor switchgear bay. Batch production of the substation elements requires other high-tech solutions, namely non-ferrous foundry. Two machines (3D-printers owned by Automated Electrical Systems dept.) are used for the purpose of manufacturing the substation prototype: StarLight 3Dprinter (made in Russia) employed for printing small details with high accuracy, and CubeX 3D-printer (made in USA) utilized for printing large elements, flashing avtions

The fourth stage implies components surface finish processing - mechanical peeling-off and deburring, removing the printing frame necessary for printing, cleaning, light-striking and drying in the UV-camera. After that the primary base coating and the painting processes are performed, the substation bay is prepared for assembly and then assembled. 


\section{Conclusion}

To date the technical drawings have been completed and 3D-printing has been partly complete for the following equipment: SVEL TDN 110/20 kV 40 MVA transformer, Mosizolyator $110 \mathrm{kV}, 66 \mathrm{kV}$ and $20 \mathrm{kV}$ bushings, UETM VEB-110 kV circuit breaker, UETM TRG-110 current transformer, AIZ SO-110 kV busbar post insulator, Global Insulator Group overhead line hardware and insulation, Arutti rigid busbar. The following equipment is at the stage of three-dimensional drawings UETM RPD-110 kV switch, UETM ZNG$110 \mathrm{kV}$ voltage transformer, SVEL high-frequency choke, and DECRA CMA coupling capacitor. The $110 \mathrm{kV}$ substation bay was developed with maximum elaboration and detailing. Its prototype model is in production using heliocomposite and plastic materials in the scale of $1 / 10$.

\section{Future Opportunities}

The search is underway for high-tech solutions addressing the requirements of batch production. At the same time, the substation bay systematic assembly tutorial is in progress. The non-ferrous metals types and alloys research is conducted. The overall $110 \mathrm{kV}$ outdoor switchgear bay project scope includes:

1) $110 \mathrm{kV}$ substation three-dimensional technical drawings;

2) $110 \mathrm{kV}$ substation two-dimensional technical drawings;

3) $110 \mathrm{kV}$ substation design educational guidance;

4) $110 \mathrm{kV}$ substation design information graphics posters;

5) $110 \mathrm{kV}$ substation static prototype model in the scale of $1 / 10$;

6) $110 \mathrm{kV}$ substation static prototype assembly tutorial;

7) $110 \mathrm{kV}$ substation operational model in the scale of $1 / 10$.
In the future $110 \mathrm{kV}$ substation outdoor switchgear bay in the scale of $1 / 10$ will allow to aid numerous educational activities - laboratory classes and practical training: design, construction, installation, routine switching etc. The technical drawings and static prototype are expected to be complete by the end of 2018.

\section{Acknowledgement}

The work was supported by Act 211 Government of the Russian Federation, contract № 02.A03.21.0006 and the Ministry of Education and Science of Russian Federation (in the framework of state assignment, № 13.1928.2014/K (project № 1928)).

\section{References}

1. O. Vozisova., A. Egorov, A. Trembach. Designer of electric power systems. Siemens 3API DT $145 \mathrm{kV}$ Circuit-Breaker // Applied Mechanics and Materials. Vol. 698 (2015). pp. 699-703. Submitted (C) 07.10.2014 (2015) Trans Tech Publications, Switzerland

2. Fröhlich C. and Markus M. Terrestrial laser scanning-new perspectives in 3D surveying. International archives of photogrammetry, remote sensing and spatial information sciences 36.Part 8 (2004): W2.

3. A. Tavlintsev, S. Eroshenko, P. Kuzin, A. Kazantsev, A. Trembach, Vozisova O., E. Koksharova, N. Zhavrid, V. Kunshin, P. Bannih, Baltin D. 220/110 kV 250 MVA Autotransformer kit. Advanced Materials Research, 1008-1009. pp. 1162-1165 